\title{
icalunme
}

\author{
International Conference On Advanced research \\ in Business, Management and Economics \\ 29-31 March Prague, Czech Republic
}

\section{The Moderating effect of corporate brand experience on brand image in event sponsorship: Conceptual and methodological approach}

\author{
Zineb benyahya \\ University of juridical, economic, and social sciences, Mohamedia
}

\begin{abstract}
The impact of sponsorship on the brand image has been barely studied, This research aims to reach a double contribution: On the one hand, it demonstrates the originality of event sponsorship as a means of communication, persuasive allowing an enrichment of brand equity, on the other hand, it introduces the concept of brand experience of the sponsor during the action of the sponsorship, as an explanatory variable to enhance the effectiveness of the sponsorship in terms of image transfer of the entity sponsored to the sponsor.

We review the concept of event sponsorship, then conducting a research on the effects on the brand image. As a reference to the literature review, we formulate several hypotheses concerning the effects of an event sponsorship operation on the image of the sponsor brand, and a number of variables moderating its effectiveness, namely the brand experience.

Answers to the question of how brand image is influenced by the on-site practices of a sponsorship is first developed on a theoretical basis, As well as many research questions, a mix of research methodologies is indicated to allow choosing the best-fitting methodology for each research step.
\end{abstract}

Keywords: Brand image, Efficiency, Event sponsorship, Image transfer, brand experience, methodological approach 